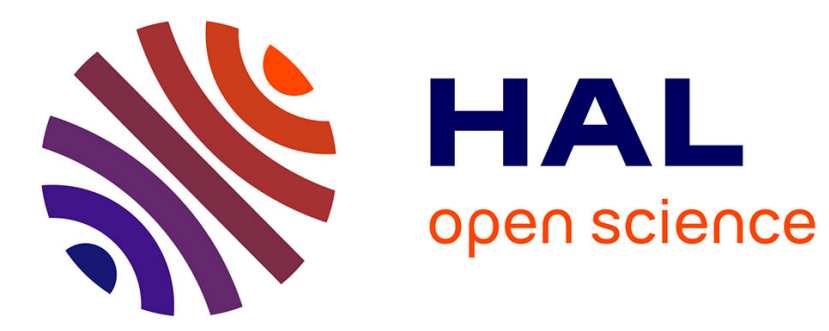

\title{
Age and input in the acquisition of grammatical gender in Dutch
}

Sharon Unsworth

\section{To cite this version:}

Sharon Unsworth. Age and input in the acquisition of grammatical gender in Dutch. Second Language Research, 2008, 24 (3), pp.365-395. 10.1177/0267658308090185 . hal-00570748

\section{HAL Id: hal-00570748 \\ https://hal.science/hal-00570748}

Submitted on 1 Mar 2011

HAL is a multi-disciplinary open access archive for the deposit and dissemination of scientific research documents, whether they are published or not. The documents may come from teaching and research institutions in France or abroad, or from public or private research centers.
L'archive ouverte pluridisciplinaire HAL, est destinée au dépôt et à la diffusion de documents scientifiques de niveau recherche, publiés ou non, émanant des établissements d'enseignement et de recherche français ou étrangers, des laboratoires publics ou privés. 


\section{Age and input in the acquisition of grammatical gender in Dutch}

\section{Sharon Unsworth Utrecht University}

Received March 2007; revised September 2007; accepted December 2007

This article investigates the effect of age of first exposure and the quantity and quality of input to which non-native acquirers (L2ers) are exposed in their acquisition of grammatical gender in Dutch. Data from 103 English-speaking children, preteens and adults were analysed for gender agreement on definite determiners. It was observed that although most learners regularly overgeneralized the common gender definite determiner de to neuter nouns, there also existed child and adult L2ers who consistently produced the target neuter determiner het with these nouns (contra Carroll, 1989; Hawkins and Franceschina, 2004; Franceschina, 2005). Participants in all three groups produced het equally frequently with nonderived nouns as with diminutives, one of the few reliable morphophonological cues for neuter gender (compare Carroll, 1999). The present findings are evaluated in light of previous research (Hulk and Cornips, 2006a) suggesting that the quality of input to which L2ers are exposed may significantly affect their ability to proceed beyond the aforementioned stage of overgeneralization. Evidence for frequency effects and the observation that targetlike performance correlated with length of exposure suggests that quantity of input is a significant factor in the acquisition of Dutch gender. This is to be expected if the acquisition of gender is for a large part word-learning (Carroll, 1989; Montrul and Potowski, 2007)

Keywords: grammatical gender, Dutch, age effects in L2, input in L2, child L2 acquisition

Address for correspondence: Sharon Unsworth, Department of English and Utrecht Institute for Linguistics, Utrecht University, Trans 10, 3512JK Utrecht, The Netherlands; email: sharon. unsworth@let.uu.nl 


\section{Introduction}

One of the most frequent observations made about non-native (L2) adults is that they stop short, or fossilize, before reaching nativelike levels of ultimate attainment (e.g. Bley-Vroman, 1990). In contrast, L2 children are observed - and to a certain extent are assumed - to regularly attain native levels of competence (for relevant discussion, see Hyltenstam and Abrahamsson, 2003). This discrepancy is often interpreted as reflecting a fundamental difference in the cognitive processes employed by children and adults in the language acquisition process.

One phenomenon that is known to cause persistent problems for many L2 adults - even after lengthy exposure to the target language in question - is grammatical gender. Although essentially a property of individual nouns, grammatical gender - instantiated in languages such as French, German, Swedish - is generally only detectable on words associated with the noun that agree with it, such as definite and indefinite determiners and adjectives. Several studies have observed that even after considerable exposure to the target language in question, L2 adults regularly fail to provide appropriately gender-marked determiners and adjectives (see, for example, on Romance languages: Carroll, 1989; Dewaele and Véronique, 2001; Bruhn de Garavito and White, 2002; Franceschina, 2005; on Swedish: Andersson, 1992; Hyltenstam, 1992; on German: Rogers, 1987).

Various proposals have been put forward to account for adult L2ers' poor performance in this domain. For example, proponents of the Failed Functional Features Hypothesis (Hawkins and Chan, 1997) link L2 failure to the absence of grammatical gender in the learner's first language (L1) (Hawkins and Franceschina, 2004; Franceschina, 2005; see also Carroll, 1989). On this proposal, post-puberty learners are unable to acquire functional features that are not represented in their L1. Thus, when acquiring a language with grammatical gender, the interlanguage grammars of adult L2ers whose L1 does not instantiate grammar are always subject to a representational deficit.

Other researchers have, however, noted that adult L2ers' problems with gender are not restricted to those L2ers whose L1 does not instantiate grammatical gender (Bruhn de Garavito and White, 2002). Furthermore, there is evidence that L2ers with an L1 without gender are 
able to represent this category in their interlanguage grammars: White et al. (2004) present data from advanced L1 English learners of Spanish who do not differ from native speakers or from francophone L2ers in their production and comprehension of gender-marked determiners and adjectives. These authors furthermore observe that the errors that learners make predominantly consist of the use of a default form (see Bartning, 2000, who observes essentially random behaviour). Bruhn de Garavito and White (2002: 170) suggest, following Lardiere (2000) and Prévost and White (2000), that learners experience a mapping problem between syntax and morphology, that is, they experience 'difficulties in relating underlying abstract features to appropriately inflected surface forms'.

Turning now to younger L2ers, Guillelmon and Grosjean (2001) observe that L2 English-French children whose average age of first exposure was around five successfully distinguish incongruent from congruent determiner-noun combinations. In contrast, the L2 adults in their study failed to make such a distinction. Andersson (1992) observes that while L2 children and adults acquiring Swedish commit qualitatively similar errors, the number of errors is considerably lower for the children. Other studies have, however, observed that even L2 children, widely assumed to reach nativelike levels of ultimate attainment, experience problems with grammatical gender (e.g. Carroll, 1989; Hulk and Cornips, 2006a). Carroll (1989) reports that Englishspeaking children in both early and late immersion programmes in French-speaking Canada regularly fail to produce targetlike gendermarked determiners and adjectives. It is, however, possible that at the time of testing these children had not yet reached their end state.

The acquisition of grammatical gender requires learners to distinguish those grammatical categories that are involved in the gender system from those that are not (Carroll, 1999: 45). They must notice, for example, that the morphological form of the determiner varies depending on the (form of the) noun with which it occurs. Where available, learners may make use of semantic and morphological cues (Carroll, 1999) but, in the absence of such cues, they must essentially acquire the gender for each noun on a case-by-case basis. As such, exposure to sufficient input (whatever that might be) is crucial for the targetlike acquisition of grammatical gender to take place. 
The goals of the present article are twofold:

- to investigate the role of age in the L2 acquisition of grammatical gender for a new population, namely English-speaking child and adult learners of Dutch; and

- to examine the role of the quality and quantity of input to which L2ers are exposed and the extent to which this has an effect on their linguistic development.

The article is organized as follows. The next section details the gender system in Dutch and reviews some of the previous acquisition literature; it also contains the specific research questions to be addressed in the current study. Section II presents the learner data and, finally, Section III compares the results of the current study with those observed in previous work.

\section{Acquisition of gender in Dutch}

The Dutch gender system makes a distinction between common and neuter gender (for an overview, see the introduction to this issue). Gender is visible on definite determiners, relative and demonstrative determiners and adjectives and, as for many other languages, gender attribution is based on the form of the definite determiner (Corbett, 1991). This means that when a noun is preceded by the definite determiner de, as in de muis 'the mouse', it is classified as common, and when the definite determiner is het, as in het huis 'the house', it is classified as neuter. In building the syntactic structure of the Determiner Phrase (DP) however, it is of course the gender of the noun that determines the form of any agreeing elements (for relevant discussion, see Van Berkum, 1996).

Following Carstens (2000), nouns are assumed to bear an interpretable gender feature which checks (or values) the uninterpretable gender features on agreeing determiners and adjectives. The noun moves covertly (i.e. at Logical Form, LF) to Num, the head of the Number Phrase (1), to check the features of the adjective in a spec-head relation (compare Romance languages, where this movement is overt), and to the head of the Determiner Phrase, D, to check the features of the determiner in a head-head relation. 


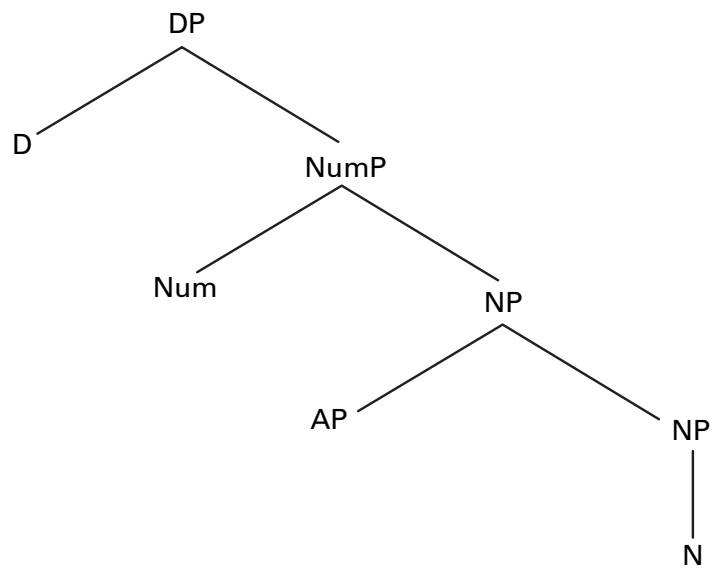

For French, the feature [ \pm feminine] has been suggested (Carroll, 1989). By analogy, the appropriate feature in Dutch may be [ \pm neuter] (compare $[ \pm \mathrm{DE}]$ proposed by Deutsch and Wijnen, 1985). Common gender is considered the default.

The gender specification of a given noun is generally assumed to be arbitrary (e.g. Geerts et al., 1984; Donaldson, 1987). Although a number of morphophonological and semantic regularities exist, there are many more nouns that are not covered by these 'rules' and, perhaps more importantly, there are frequent exceptions (Geerts et al., 1984: 41-49; Donaldson, 1987: 27-33). For example, names of musical instruments have common gender (but compare, for example, het klavier 'the piano'), and words ending in -isme and -um are neuter (but compare de petroleum 'the petrol'). There is, however, one frequently occurring, unambiguous morphophonological cue for neuter gender, namely the diminutive suffix -je. All diminutives, such as hondje 'little dog', are neuter, even when derived from a common noun, as is hond 'dog'. Gender acquisition in Dutch is complicated even further by the fact that common nouns are approximately twice as frequent as neuter nouns (van Berkum, 1996). De is also used for plural nouns of both genders. Consequently, de is much more frequent than het in the language learner's input.

Previous studies on the monolingual L1 acquisition of gender in Dutch indicate that it is a gradual process (e.g. Verrips and Wijnen, 
1998). Van der Velde $(2003 ; 2004)$ observes that children overgeneralize $d e$ with neuter nouns until at least age six, producing, for example, de raam 'the window' instead of the target het raam. There is no overgeneralization in the other direction, however: het is not produced with common nouns; for similar results on bilingual L1 (2L1) English/ Dutch, see De Houwer (1990).

In a series of studies, Cornips and Hulk (2005; this issue; Hulk and Cornips, 2006a; 2006b) investigate the acquisition of grammatical gender in ethnic community children in the Netherlands with a variety of L1s. ${ }^{1}$ They observe that although, like monolinguals, the bilingual children overgeneralize $d e$ to neuter nouns, there is a quantitative difference between the bilinguals and monolinguals in that the acquisition of het is delayed. Hulk and Cornips argue that there also appears to be a qualitative difference between the two groups, as the data suggest that the L2/2L1 children fossilize in the non-targetlike stage of overgeneralization (compare also Brouwer et al., 2008). A similar pattern of overgeneralization is observed by Blom et al. (this issue) in their study of ethnic community children and adults with Moroccan Arabic and/or the Berber language Tarifit as L1.

Hulk and Cornips (2006a) speculate that deficient input may be the cause of the quantitative and qualitative differences between the monolinguals and bilinguals. Bilingual children are exposed to quantitatively less input than monolingual children, and this may lead to a delay in the acquisition of het. As noted above, despite the existence of a number of regularities, gender assignment in Dutch remains for the large part random and, as such, the acquisition of gender to a certain extent boils down to word-learning (Carroll, 1989: 567). Although learners may make use of semantic and morphological cues (Carroll, 1999), in the absence of such cues, the gender for each noun must essentially be acquired on a case-by-case basis. Lexical development is clearly affected by the input; according to Umbel and Oller (1995) and Anderson (1999), reduced input can greatly affect the lexical development of bilinguals. It is therefore unsurprising that Hulk and Cornips (2006a) observe that bilingual children should experience a delay in the

\footnotetext{
${ }^{1}$ The learning situation of the children in Hulk and Cornips' study shares characteristics of both 2L1 and child L2 acquisition (Hulk and Cornips, 2006a: 114).
} 
acquisition of grammatical gender in Dutch (for relevant discussion, see Montrul and Potowski, 2007).

Hulk and Cornips (2006a) also argue that the input to which the bilinguals in their study are exposed is qualitatively different from that to which monolinguals are exposed because it includes overgeneralization of $d e$ by the older community members who acquired Dutch as an adult (Cornips, 2002). They claim that this qualitative difference in the input may have led the L2/2L1 children in their study to fossilize in a non-targetlike stage of overgeneralization.

Sabourin et al. (2006) claim that the morphological similarity between L1 and L2 are crucial for successful acquisition of grammatical gender. They observe that L2 adults - whose L1, German, patterns similarly to Dutch in terms of gender assignment and agreement - are better at gender in Dutch than L2 adults with a Romance language as L1, and this latter group of learners is, in turn, better than L1 English speakers (see also Sabourin and Stowe, this issue). In addition, these authors observe clear frequency effects in their results: irrespective of L1, all L2ers produce the targetlike determiner more often on high frequency nouns than on low frequency nouns.

\section{Research questions}

This article investigates the role of two factors - age and input - in the acquisition of Dutch gender by English-speaking children and adults. The first research question asks whether there is evidence for age effects in the L2 acquisition of gender. In the present study, the existence of an age effect will be determined by evaluating the rate at which a nativelike distinction is made between neuter and common nouns in gender assignment as measured by determiner use and types of errors which the child and adult groups make. If the representational deficit approach put forward by Hawkins and Franceschina (2004) is correct, L2 adults should score significantly worse than L2 children in this domain. It is, however, possible that they still make use of any morphological and semantic cues for gender that are available (Carroll, 1999). For Dutch, this would predict that L 2 adults produce the target determiner significantly more frequently with diminutives than with non-derived nouns. 
The second and third research questions concern the quantity and quality of input, respectively. The second research question asks whether the (child/adult) L2 acquisition of grammatical gender is affected by the reduced quantity in input that bilinguals who maintain their L1 are by definition exposed to. If the acquisition of gender to a large extent boils down to word-learning, and the acquisition of vocabulary is affected by reduced input, it is predicted that:

- those L2ers with a longer exposure to the L2 will be more targetlike than those with a shorter exposure; and

- L2ers will commit more errors on low frequency nouns than on high frequency nouns.

The third research question concerns Hulk and Cornips' (2006a) claim that the ethnic community children in their study may have fossilized in a stage of overgeneralization because their L2 input is qualitatively different from that of their monolingual peers. Such a qualitative difference in input should not be the case for the participants in the present study: it is highly unlikely that these English-speaking learners of Dutch will have been systematically exposed to 'ethnic Dutch' (Cornips, 2002). Although the quantity of input to which some of the Englishspeaking learners are exposed may be limited, it predominantly consists of input from native speakers. While it is true that, like ethnic community learners, the English speakers in the present study may also communicate with other non-native speakers of Dutch, for many if not most, this communication is likely to occur in English rather than Dutch. Furthermore, the difference in socio-economic status between these two learner populations means that they are unlikely to come into contact with each other. Thus, it is predicted that while the participants in the present study may overgeneralize de to neuter nouns, they should not fossilize in this stage of overgeneralization. In other words, at least some of the L2ers in the present study are predicted to be targetlike.

\section{Testing a new population: English/Dutch L2 children and L2 adults}

\section{Participants}

The participants in the present study were 58 L2 English/Dutch children, 19 L2 English/Dutch preteens and 26 L2 English/Dutch adults. 
All participants were resident in the Netherlands at time of testing. The children all attended international schools, and some had previously attended Dutch pre-school/primary schools. The children were almost exclusively from middle-class families who moved to the Netherlands for professional purposes. The majority of the adults were highly educated and they had moved to the Netherlands for professional or personal reasons. For the $\mathrm{L} 2$ children, age at first exposure ranged from birth to $7 ; 3(M=4 ; 10, S D=1 ; 9)$, age at time of testing from $5 ; 3$ to $17 ; 4$ $(M=10 ; 5, S D=3 ; 8)$ and length of exposure from $0 ; 11$ to $15 ; 2$ $(M=5 ; 6, S D=3 ; 8) .{ }^{2}$ For the L2 preteens, age of first exposure ranged from 8 to $12 ; 4(M=9 ; 6, S D=1 ; 7)$, age at time of testing from $9 ; 8$ to $18 ; 5(M=12 ; 0, S D=2 ; 4)$ and length of exposure from $0 ; 2$ to 7 years $(M=2 ; 5, S D=1 ; 11)$. For the L2 adults, age at first exposure ranged from 21 to 43 years $(M=27 ; 3, S D=5 ; 3)$, age at time of testing from $22 ; 2$ to $50 ; 0(M=34 ; 4, S D=8 ; 0)$, and length of exposure from $0 ; 4$ to 27 years $(M=6 ; 9, S D=6 ; 8)$. The variation in length of exposure means that these data can be used to investigate both development and ultimate attainment. Four adults were tested on two separate occasions; the intervening period between the two test moments ranged from 1;8 to $1 ; 10$. These test moments are counted separately in the group results. A group of 10 adult native speakers of Dutch were also tested (aged 18 to 52 years; $M=28$ years).

\section{Method}

Semi-spontaneous data were collected using a picture description task (designed for other purposes; see Unsworth, 2005), where participants had to describe series of pictures. Each participant saw one of two different sets of pictures; the data are thus relatively consistent in terms of types of nouns produced. Using semi-spontaneous data means that there was a different number of tokens per participant: on average, 18.3 for common nouns and 12.1 for neuter nouns. There was no significant difference between the three L2 groups in number of tokens produced (common nouns: $F(2,10)=1.08, p>.05$; neuter nouns: $F(2,10)=.34$, $p>.05)$.

\footnotetext{
${ }^{2}$ The children in the present study clearly differ from those in previous studies in terms of the social setting in which they acquire Dutch, and, in general, their age of first exposure is also slightly older (compare Cornips and Hulk, this issue). There are, however, participants in the child group who were first exposed to Dutch at a similar age to the children in Hulk and Cornips' (2006a) study.
} 


\section{Group results}

As stated in Section I.2, the focus of the present study is gender attribution as measured by agreement of the definite determiner with the noun. The group results are presented in Table 1. One child and one preteen failed to produce any neuter nouns and are hence excluded from analysis for that category.

As a group, the native controls almost always produced de with common nouns and het with neuter nouns. In each of the L2 groups, most common nouns were correctly produced with $d e$, whereas less than half of neuter nouns were produced with het. The common determiner was thus overgeneralized to neuter nouns and, at first glance at least, it appears that overgeneralization in the other direction - that is, of het to common nouns - did not really occur.

The age of first exposure for participants in the child L2 group ranged from birth to seven years, that is, this group included both simultaneous and successive bilingual children. In order to determine whether there was an effect of age of first exposure for this group, the group was further subdivided into:

- a child L2 group, consisting of children whose age of first exposure was between four and seven years $(n=44)$; and

- a child L2/2L1 group, consisting of children whose age of first exposure was between birth and four years $(n=13)$.

There were no significant differences between these two groups for common (Mann-Whitney: $z=-.25, p>.05$ ) or neuter nouns (MannWhitney: $z=-.90, p>.05) .{ }^{3}$ They are therefore analysed as one group henceforth.

Table 1 Percentage of common and neuter nouns produced with target determiner (numbers in brackets): all participants

\begin{tabular}{lll}
\hline Group & Common (de) & Neuter (het) \\
\hline L2 children & $90.8(971 / 1069)$ & $25.4(171 / 674)$ \\
L2 preteens & $92.8(362 / 390)$ & $17.1(40 / 233)$ \\
L2 adults & $94.8(474 / 500)$ & $45.8(179 / 181)$ \\
Native controls & $98.3(178 / 181)$ & $96.9(186 / 192)$ \\
\hline
\end{tabular}

\footnotetext{
${ }^{3}$ Wherever data do not conform to the prerequisites for a parametric test, non-parametric tests are employed (Mann-Whitney for two independent samples, Kruskal-Wallis for more than two independent samples and Wilcoxon Signed Ranks for two related samples).
} 
The difference between the groups in Table 1 was significant for neuter nouns $(F(3,11)=21.27, p>.001)$ but not for common nouns $(F(3,11)=.69, p>.05)$. Games-Howell post hoc tests revealed that the native controls differed significantly from the L2 children $(M D=73.5 \%, p<.001)$, the L2 preteens $(M D=78.4 \%, p<.001)$ and the $\mathrm{L} 2$ adults $(M D=57.4 \%, p=.001)$. The children did not significantly differ from the preteens $(M D=4.8 \%, p>.05)$ or from the $\mathrm{L} 2$ adults $(M D=-16.1 \%, p>.05)$, but the preteens were significantly different from the $\mathrm{L} 2$ adults $(M D=21.0 \%, p<.05)$.

In addition to age of first exposure, a number of other factors may affect participants' knowledge of grammatical gender. These include general level of L2 proficiency and length of exposure and type of exposure. Type of exposure refers to the intensity with which learners were confronted with Dutch input. Proficiency in the present context was determined using a measure developed in Unsworth (2005), which, crucially, did not incorporate gender. ${ }^{4}$ When groups were divided into sub-groups on the basis of these factors, the percentage of common nouns produced with de remained more or less constant, whereas the percentage of neuter nouns produced with het generally rose with increasing proficiency, longer exposure and more intensive exposure (for relevant discussion, see Unsworth, 2007).

Use of het with neuter nouns correlated moderately with proficiency $(r(105)=.51, p<.001)$ and with length of exposure $(r(105)=.48$, $p<.001)$ and weakly with type of exposure $(r(105)=.35, p<.001)$ and age at first exposure $(r(105)=.211, p>.05)$. A multiple regression analysis indicated that proficiency was the best predictor of use of het with neuter nouns $(\beta=.31, t(105)=2.95, p>.01)$, followed closely by age of first exposure $(\beta=.21, t(105)=2.43, p>.05)$. Taken together, these two factors explained almost a quarter of the variance in the use of het with neuter nouns $\left(R^{2}=.24, F(2,104)=16.35, p<.001\right)$.

Table 2 and Table 3 present the data for the three L2 groups when divided according to proficiency and length of exposure respectively. There were three proficiency groups: low, mid and high. There was no significant difference between the three proficiency levels on common

\footnotetext{
${ }^{4}$ Using semi-spontaneous oral data, this measure combines three separate scores (verbal density, lexical diversity and percentage of error-free utterances) to form a single proficiency score (for more details, see Unsworth, 2005: Chapter 4; 2008).
} 
nouns for any of the L2 groups (L2 children: $F(2,55)=2.07, p>.05 ; \mathrm{L} 2$ preteens: $F(2,16)=1.05, p>.05$; L2 adults: $F(2,27)=.531, p>.05)$. Games-Howell post hoc tests revealed that the only significant difference between proficiency levels was between the low and high proficiency groups for the $\mathrm{L} 2$ children $(M D=-40.4 \%, p>.001)$ and the L2 adults $(M D=-33.7 \%, p=<.05)$, although for the $\mathrm{L} 2$ children the difference between the low and mid groups $(M D=-16.5 \%, p=.06)$ and the mid and high groups was also approaching significance $(M D=-23.9 \%$, $p=.07)$. There were no significant differences between the child, preteen and adult groups at any level (Kruskal-Wallis: low: $\chi^{2}(2)=4.24$, $p>.05$; mid: $\chi^{2}(2)=5.33, p>.05$; high: $\chi^{2}(2)=.50, p>.05$ ). For all three groups, the use of het with neuter nouns thus increased significantly with increasing proficiency, but the scores for the high proficiency groups remained rather low.

Table 3 presents the data for participants divided according to length of exposure. Participants were divided into three (arbitrarily defined) groups: short exposure $(0 ; 2-3 ; 6)$, medium exposure $(3 ; 8-8 ; 2)$ and long exposure (8;5-27). There was no significant difference between the various length of exposure groups on common nouns for the L2 children $(F(2,55)=1.01, p>.05)$ the L2 preteens $(z=-.85, p>.05)$ or for L2 adults $(F(2,27)=1.65, p>.05)$. There was a significant difference between groups on neuter nouns for the L2 children $(F(2,54)=9.59$, $p<.001)$ and for the L2 adults $F(2,27)=5.69, p<.01)$, but not for the

Table 2 Percentage of common and neuter nouns produced with target determiner (numbers in brackets): participants grouped according to proficiency

\begin{tabular}{lcc}
\hline Proficiency group & Common (de) & Neuter (het) \\
\hline L2 children: & & \\
Low $(n=23)$ & $97.9(332 / 339)$ & $5.3(11 / 209)$ \\
Mid $(n=15)$ & $86.0(302 / 351)$ & $23.5(50 / 213)$ \\
High $(n=20)$ & $88.9(337 / 379)$ & $43.7(110 / 252)$ \\
L2 preteens: & & \\
Low $(n=6)$ & $87.1(108 / 124)$ & $2.5(17 / 69)$ \\
Mid $(n=8)$ & $97.3(144 / 148)$ & $12.0(11 / 92)$ \\
High $(n=5)$ & $93.2(110 / 118)$ & $16.7(12 / 72)$ \\
L2 adults: & & \\
Low $(n=8)$ & $97.7(126 / 129)$ & $20.9(19 / 91)$ \\
Mid $(n=8)$ & $90.2(111 / 123)$ & $56.7(59 / 104)$ \\
High $(n=14)$ & $95.6(237 / 248)$ & $51.5(101 / 196)$ \\
\hline
\end{tabular}


Table 3 Percentage of common and neuter nouns produced with target determiner (numbers in brackets): participants grouped according to length of exposure

\begin{tabular}{|c|c|c|}
\hline Length of exposure & Common (de) & Neuter (het) \\
\hline $\begin{array}{l}\text { L2 children: } \\
\text { Short }(n=24) \\
\text { Medium }(n=20) \\
\text { Long }(n=14)\end{array}$ & $\begin{array}{l}95.3(389 / 408) \\
89.6(379 / 423) \\
84.5(191 / 226)\end{array}$ & $\begin{array}{r}9.8(24 / 244) \\
25.4(72 / 283) \\
51.0(75 / 147)\end{array}$ \\
\hline $\begin{array}{l}\text { L2 preteens: } \\
\text { Short }(n=15) \\
\text { Medium }(n=4) \\
\text { Long }(n=0)\end{array}$ & $\begin{array}{c}92.9(300 / 323) \\
92.5 \quad(62 / 67) \\
-\end{array}$ & $\begin{array}{c}18.0(35 / 194) \\
12.8 \quad(5 / 39) \\
-\end{array}$ \\
\hline $\begin{array}{l}\text { L2 adults: } \\
\text { Short }(n=13) \\
\text { Medium }(n=9) \\
\text { Long }(n=8)\end{array}$ & $\begin{array}{l}98.1(210 / 214) \\
93.3(154 / 165) \\
90.9(110 / 121)\end{array}$ & $\begin{array}{l}28.4(40 / 141) \\
45.8(70 / 153) \\
71.1 \quad(69 / 97)\end{array}$ \\
\hline
\end{tabular}

L2 preteens $(z=-.22, p>.05)$. The only significant differences for both the child and adult groups were between the short and the long groups (L2 children: $M D=-39.6 \%, p<.01$; L2 adults: $M D=-42.1 \%$, $p<.05$ ), although the difference between the long and medium groups was approaching significance in the child group $(M D=-16.8 \%$, $p=.06)$. Amongst learners with a short length of exposure, there was a significant difference between the L2 children and adults $(z=-2.55$, $p<.05)$, but there were no differences between the various age groups amongst those with a medium $(F(2,30)=1.22, p=>.05)$ or a long $(t(20)=-1.12, p>.05)$ length of exposure.

Summarizing, the results indicate that children and adults consistently produced $d e$ with common nouns but, on the whole, they regularly failed to produce het with neuter nouns; when sub-divided on the basis of proficiency and length of exposure, the adults tended to be more targetlike than the children, but this difference was not always reflected in the statistics.

\section{Individual results}

Both child and adult groups generally failed to produce het with neuter nouns. The question is whether this stems from widespread failure or whether these group results hide some participants who consistently combined neuter nouns with het. To address this question, an individual analysis was conducted. 
a Response patterns: Participants were categorized according to the response patterns they produced in different determiner/noun combinations. This analysis included only those participants who produced at least five tokens for each of the two genders. Thirteen children, five preteens and one adult were thus excluded. The results are presented in Table 4, where a tick indicates that $20 \%$ or more of the nouns of a given category are produced with the respective determiner. A tick in either the de or the het column only therefore indicates that participants consistently produced common nouns with one determiner, where consistency is operationalized as $80 \%$, meaning minimally $4 / 5$ or $5 / 5$ cases. $^{5}$

Six different patterns were attested in the data. In Pattern 1, which accounts for just over half of all participants $(54.5 \%$ (48/88)), both common and neuter nouns were consistently produced with de. Het was not produced (or, to be completely accurate, it was not produced at a rate higher than 20\%). In Pattern 2, the second most frequent pattern, $d e$ was used with common nouns, and both de and het were used with neuter nouns. In Pattern 3, de and het were used with both types of nouns, whereas in Pattern 4 neuter nouns occurred exclusively with het, but het was also used with common nouns, along with de. In Pattern 5, het was used with both neuter and common nouns; there was no de (or, more accurately, de was not produced at a rate higher than $20 \%$ ). Finally, in Pattern 6, de and only de was consistently used with

Table 4 Distribution of de and het with common and neuter nouns: individual response patterns

\begin{tabular}{|c|c|c|c|c|c|c|c|}
\hline \multirow[b]{2}{*}{ Pattern } & \multirow[b]{2}{*}{ L2 children $(n)$} & \multirow[b]{2}{*}{ L2 preteens $(n)$} & \multirow[b]{2}{*}{ L2 adults $(n)$} & \multicolumn{2}{|c|}{ Common } & \multicolumn{2}{|c|}{ Neuter } \\
\hline & & & & de & het & de & het \\
\hline 1 & 27 & 8 & 13 & $\checkmark$ & & $\checkmark$ & \\
\hline 2 & 11 & 4 & 10 & $\checkmark$ & & $\checkmark$ & $\checkmark$ \\
\hline 3 & 2 & 2 & 0 & $\checkmark$ & $\checkmark$ & $\checkmark$ & $\checkmark$ \\
\hline 4 & 3 & 0 & 3 & $\checkmark$ & $\checkmark$ & & $\checkmark$ \\
\hline 5 & 1 & 0 & 0 & & $\checkmark$ & & $\checkmark$ \\
\hline 6 & 1 & 0 & 3 & $\checkmark$ & & & $\checkmark$ \\
\hline
\end{tabular}

Note: The target is shaded grey

\footnotetext{
${ }^{5}$ By adopting the $80 \%$ criterion with a minimum of 5 tokens per gender, it is possible to characterize the participants' behaviour with some reliability whilst at the same time maximizing the amount of usable data by allowing for the fact that the number of tokens per participant was not always equally high (compare Section II.2).
} 
common nouns and het and only het was consistently used with neuter nouns. There are three adults and one child with this response pattern; these participants systematically distinguished neuter from common nouns in terms of their determiner usage.

The lowest native score for neuter nouns was $84.2 \%$ (16/19). Five children and five adults score equally high or higher. Their average length of exposure was $11 ; 6$, ranging from five to 25 years, and for all 10 participants, exposure was (quite) extensive. There is, however, just one (child) participant who falls within native-speaker range on both neuter and common nouns (lowest scoring native: 93.8\% (15/16)). She was first exposed to Dutch at age 3;4, and she had been extensively exposed to Dutch for 11 years, including one year at a Dutch-speaking primary school.

b Item consistency: The individual results presented above indicate that there were some participants who produced neuter nouns with het some or most of the time, suggesting that they have (some) knowledge of grammatical gender in Dutch. To be certain that this is the case, we need to determine whether participants produced het with the same noun consistently (for some nouns at least). To this end, data from all participants who produced more than one token of the same type were analysed for consistency, that is, whether each token of the same type was produced with the target determiner.

Most participants (47 younger children, 11 older children and 33 adults) produced at least one type of neuter noun more than once and of these (in total) 270 nouns, $19.6 \%(n=53)$ consistently (i.e. $\geq 80 \%$ of tokens) occurred with the target determiner het, $55.6 \%(n=150)$ consistently occurred with $d e$, and $24.8 \%(n=67)$ occurred with both $d e$ and het. Using de and het with all or most nouns could indicate random behaviour. Of the 25 children, six preteens and 20 adults who used the neuter determiner at all and who produced more than two different nouns with more than one token, there are no preteens, just three children (12\%) and six adults (30\%) who used both de and het with the majority of noun types. These figures suggest that although the proportion of participants with apparently random behaviour is low for all groups, the adults were possibly less consistent in their determiner use than the children and preteens; however, we cannot rule out the possibility that inconsistent determiner use across nouns may also result from the learner acquiring the neuter gender of the nouns in question at the same time. 
Turning now to the common nouns, the vast majority were consistently used with the target determiner $d e$. There were a number of participants - namely those with Patterns 3,4 and 5-who regularly used het with common nouns, however. This behaviour could reflect the learner's miscategorization of a particular noun as neuter or a failure to categorize a noun as either neuter or common, it could be the result of the overgeneralization of het, or it could be purely random. If it is random, participants are expected to produce both de and het with the majority of nouns. If it stems from the miscategorization or lack of categorization of certain nouns, a number of nouns should be consistently produced with het or with de and het and the rest with de, whereas if it is the result of overgeneralization, most nouns are expected to be produced with het most of the time.

There were 16 children, five preteens and three adults who produced het with a common noun of which they produced two or more tokens. When compared with other common nouns with two or more tokens, the following pattern emerges. The vast majority of participants (11 children, four preteens children and all three adults) produced het with one or two different nouns at a rate of between $25 \%$ and $100 \%$, and the remaining between three and eight common nouns were produced consistently ( $\geq 80 \%$ of tokens) with de. Three children used het with all common nouns of which they produced two or more tokens some or all of the time. They did produce $d e$, but this was with nouns for which there was one token only. For the two remaining children there were not enough data to establish a pattern. The remaining preteen sometimes produced het with four different nouns and the remaining three nouns were consistently produced with $d e$.

These data suggest that the vast majority of participants have either miscategorized or have yet to categorize certain neuter nouns as neuter. Three children appeared to overgeneralize het, although de did exist in their production. There was no evidence that the use of het with common nouns was completely random.

c Longitudinal data: As noted in Section II.1, four adult participants were tested on two separate occasions. The data for these participants are presented in Table 5 . 
Table 5 Longitudinal data for four adult participants

\begin{tabular}{|c|c|c|c|}
\hline Time & $\begin{array}{l}\text { Length of } \\
\text { exposure }\end{array}$ & $\begin{array}{l}\text { Common nouns } \\
\text { with de (percent) }\end{array}$ & $\begin{array}{l}\text { Neuter nouns } \\
\text { with het (percent) }\end{array}$ \\
\hline $\begin{array}{l}\text { A25C14P: } \\
\text { Time } 1 \\
\text { Time } 2\end{array}$ & $\begin{array}{l}1 ; 3 \\
3 ; 2\end{array}$ & $\begin{array}{ll}100 & (10 / 10) \\
100 & (20 / 20)\end{array}$ & $\begin{array}{lr}0 & (0 / 5) \\
9.1 & (1 / 11)\end{array}$ \\
\hline $\begin{array}{l}\text { A11P22C: } \\
\text { Time } 1 \\
\text { Time } 2\end{array}$ & $\begin{array}{l}2 ; 2 \\
4 ; 11\end{array}$ & $\begin{array}{cc}100 & (14 / 14) \\
97.2 & (35 / 36)\end{array}$ & $\begin{array}{ll}15.4 & (2 / 13) \\
14.3 & (3 / 18)\end{array}$ \\
\hline $\begin{array}{l}\text { A17P28C: } \\
\text { Time } 1 \\
\text { Time } 2\end{array}$ & $\begin{array}{l}11 \\
13\end{array}$ & $\begin{array}{ll}100 & (26 / 26) \\
100 & (14 / 14)\end{array}$ & $\begin{array}{l}53.3(8 / 15) \\
93.3(14 / 15)\end{array}$ \\
\hline $\begin{array}{l}\text { A18P20C: } \\
\text { Time } 1 \\
\text { Time } 2\end{array}$ & $\begin{array}{l}14 \\
16\end{array}$ & $\begin{array}{cc}100 & (18 / 18) \\
73.3 & (11 / 15)\end{array}$ & $\begin{array}{ll}41.7 & (5 / 12) \\
92.9 & (13 / 14)\end{array}$ \\
\hline
\end{tabular}

Notes: Age at first exposure for participant A25C14P was 27;9 years, for A11P22C it was $24 ; 6$ years, for A17P28C is was 26 years, and for A18P20C it was 24 years.

Both participants $\mathrm{A} 25 \mathrm{C} 14 \mathrm{P}$ and $\mathrm{A} 11 \mathrm{P} 22 \mathrm{C}$ produced few (if any) neuter nouns with het at either Time 1 or Time 2, despite the latter participant moving from the low to the high proficiency group in this period. Participants A17P28C and A18P20C showed a similar pattern: at Time 1, het was used with around half of all neuter nouns and with almost all neuter nouns at Time 2. For participant A18P20C, this development was accompanied by a slight decrease in the proportion of common nouns produced with de.

\section{Analysis of neuter nouns}

Given that the acquisition of gender for a large part involves wordlearning and that lexical development is affected by reduced input, it is expected that input factors will affect the acquisition of gender and, in particular, the acquisition of marked or non-default forms (Montrul and Potowski, 2007). If this is the case, the participants in the present study should make more errors on neuter nouns and specifically on (1) neuter nouns which do not contain any morphological cue for gender, i.e. nonderived nouns, and (2) low frequency neuter nouns, as sufficient input is crucial for the successful acquisition of gender for both these types of noun. 
a Diminutives vs. non-derived nouns: Recall that the diminutive suffix -je is one of the few unambiguous morphophonological cues for gender. All diminutives are neuter. If L2ers make use of this cue, it is expected that they will perform significantly better on diminutives than on non-derived nouns.

A total of 58 participants (21/57 children, $9 / 19$ preteens and 28/30 adults) produced one or more diminutive forms. The proportion of children and preteens who produced diminutives was significantly lower than for the adults; consequently, the data must be viewed with caution as they are not completely representative. The proportion of diminutives and non-derived neuter nouns produced with het is presented for each group in Figure 1. Note that in order to ensure comparability between the two noun types, the data for the non-derived nouns is from those participants who produced diminutives only. ${ }^{6}$

There is a significant difference between the three groups on diminutives $(F(2,56)=10.56, p<.001)$. Games-Howell post hoc tests show that the significant differences were between the children and the adults

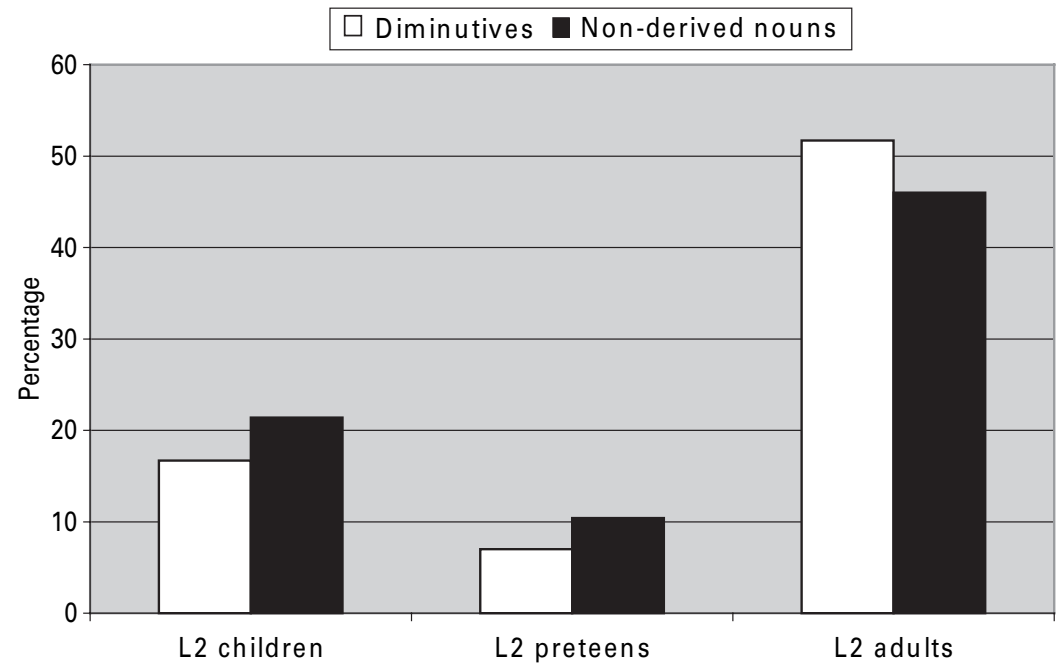

Figure 1 Percentage of diminutives and non-derived neuter nouns with het

\footnotetext{
${ }^{6}$ Six other derived neuter nouns containing an affix that could serve as a morphophonological cue for gender (compare Section I.1) were excluded from the analysis.
} 
$(M D=-38.8 \%, p<.01)$ and between the preteens and the adults $(M D=-46.2 \%, p<.001)$. For non-derived nouns, no significant difference was observed between the three groups $(F(2,55)=2.31$, $p>.05)$. Furthermore, a Wilcoxon signed-ranks test shows that there is no difference between the percentage of diminutives produced with het and the percentage of non-derived nouns produced with het for the children $(z=-.68, p>.05)$, the preteens $(z=-.42, p>.05)$ or the adults $(z=-.17, p>.05)$.

$b$ Frequency: Frequency was determined for each of the neuter nouns produced by participants using the Corpus Gesproken Nederlands 'Spoken Dutch corpus'. This corpus of nearly 9 million words encompasses speech from a variety of contexts, including face-to-face conversations, telephone conversations, lessons, news bulletins, TV commentary and debates, which on the whole can be assumed to be fairly representative of the kind of input which learners are exposed to. All derived nouns were excluded from analysis.

In general, it is the total number of occurrences of a particular word (or lemma) in a corpus which is adopted as that word's frequency value. In the present context, however, it is important to note that for the occurrence of a given noun to be informative with respect to gender, it must co-occur with other constituents that are unambiguously gendermarked. This means that occurrences of a neuter noun in plural form, for example, should not be included in the noun's frequency count because plural neuter nouns combine with $d e$. Likewise, certain nouns tend to occur in collocations where no gender-agreeing elements exist. For example, the neuter noun gevolg 'consequence' often occurs in the collocation met als gevolg 'with the result that', which (unlike its English translation) does not contain a determiner. The frequency of the nouns produced by the participants in the present study was therefore determined by counting only those tokens of a given noun that occurred in combination with some gender marked element in the DP. These included het 'the', dat 'that', dit 'this', welk 'which', ieder 'every' and elk 'each', sometimes with an adjective preceding the noun.

\footnotetext{
${ }^{7}$ For details, see http://lands.let.kun.nl/cgn/ehome.htm (March 2008).
} 
The absolute frequency for the 61 neuter nouns produced by the participants in the present study ranged from 0 to 868 . Rather than simply dividing these nouns into a high and low frequency group on the basis of some arbitrary cut-off point, the 20 nouns with the highest frequency (155 to 868) were compared with the 20 nouns with the lowest frequency (0 to 23 ) in order to ensure that a clear distinction was made between the two categories. The results are presented in Figure 2.

A cursory glance at Figure 2 indicates that both the L2 preteens and the L2 adults are better with 'higher' frequency nouns than with 'lower' frequency nouns, whereas this is not the case for the L 2 children. There is, however, no significant difference between the two types of nouns for any of the three groups (children: $t(20)=-.09, p>.05$; preteens: $t(17)=-.99, p>.05$; adults: $t(25)=-1.60, p>.05) .{ }^{8}$

\section{Discussion}

The results of the present study indicate that, consistent with previous findings, English-speaking child and adult L2ers of Dutch regularly overgeneralize the common determiner de to neuter nouns, producing non-targetlike noun phrases such as de huis 'the COMMON $_{\text {house }}$ NEUTER $^{\text {'. The }}$

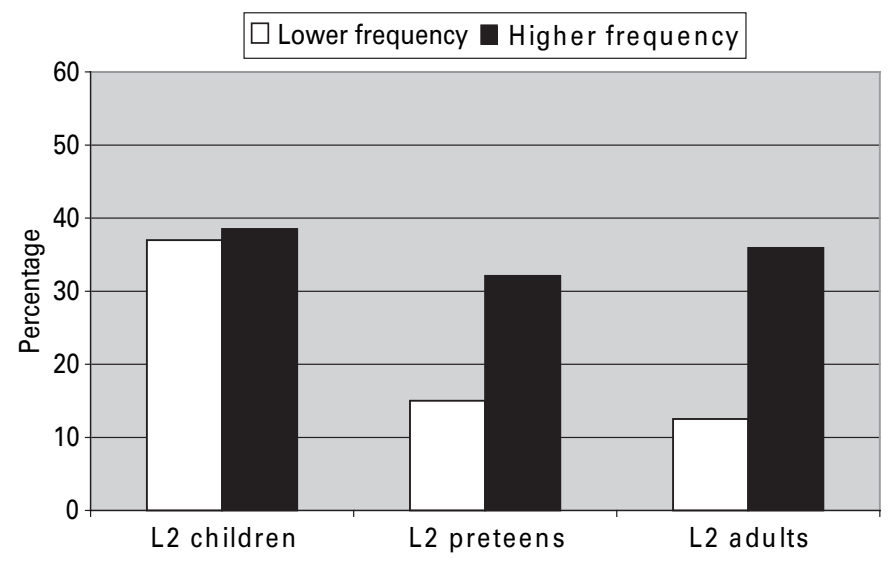

Figure 2 Percentage of 'lower' and 'higher' frequency nouns produced with het

\footnotetext{
${ }^{8}$ Levene's statistic is approaching significance for the $\mathrm{L} 2$ adults $(F=3.84, p=.06)$, suggesting that equal variances can probably not be assumed for these data. When equal variances are not assumed, the result of the $t$-test is also approaching significance $(t(21.4)=-1.95, p=.07)$.
} 
data in the present study were analysed at both the group and individual level in terms of participant characteristics (age at first exposure, length of exposure and proficiency level) and noun type (diminutive vs. non-derived, 'higher' vs. 'lower' frequency). The results of these analyses are discussed in this section in terms of the three research questions that were posed in Section I.2.

\section{Age effects}

The first research question asked whether there was any evidence for age effects in the L2 acquisition of grammatical gender in Dutch by English-speaking children and adults. It was predicted that if, as claimed by Hawkins and Franceschina (2004), the interlanguage grammars of L2 adults are subject to a representational deficit, the L2 adults should produce het with neuter nouns significantly less frequently than learners whose age of first exposure is prior to the end of a purported critical period. Assuming that the L2 preteens still fall within this period, this means that the L2 adults should score significantly worse than the L2 children and preteens. This was not the case. As observed by Andersson (1992) for the acquisition of grammatical gender in Swedish and Blom et al. (this issue) for Dutch, the child and adult participants in the present study make the same kind of errors in their use of definite determiners: most overgeneralize de to neuter nouns, and there are a limited number who use het with common nouns. Perhaps surprisingly, the L2 adults were more targetlike than both groups of younger learners. In both groups, there are participants who use het with the majority of neuter nouns and who make a clear distinction between neuter and common nouns, although these are admittedly in the minority. The preteens were consistently worse than either the adults or the children; this was probably because of their comparatively shorter length of exposure $(2 ; 5$, compare an average of $5 ; 6$ for the children and 6;9 for the adults).

A second prediction made on the basis of the representational deficit approach was that the L2 adults would produce het more frequently with neuter nouns containing a clear morphophonological cue for gender than for non-derived nouns, which do not contain such a cue. This prediction was not borne out. Although the adults produced het with diminutives 
significantly more often than either the children or the preteens, there was no significant difference between diminutive and non-derived nouns in terms of het production. This was the case for all groups. Thus, although the adults may use this cue more than the children, possibly as the result of instruction, they are not incapable of acquiring the gender of a noun when such a cue is unavailable. The observation that L2ers do not appear to make use of the diminutive form in the same way as has been claimed for monolingual L1 Dutch acquisition (van der Velde, $2003 ; 2004)$ is consistent with findings reported for Turkish/Dutch bilingual children in Cornips and Hulk (this issue).

\section{Quantity of input}

The second research question asked whether the (child/adult) L2 acquisition of gender would be affected by the reduced quantity in input which bilinguals (who maintain their L1) by definition are exposed to. It was hypothesized that this would be the case, and effects of length of exposure and of noun frequency were predicted.

The prediction of an effect of length of exposure was borne out for the L2 children and the L2 adults: length of exposure was found to correlate significantly with percentage of neuter nouns produced with het. Those participants who fell within the range of native speakers for neuter nouns had all had a lengthy and relatively extensive exposure to Dutch. Most of the L2 preteens fell in the short exposure group, which meant that it was not possible to determine any effect of length of exposure for them. With respect to the second prediction, there was a clear trend in the L2 preteen and L2 adult groups for 'lower' frequency neuter nouns to be produced with het less often than 'higher' frequency nouns, although the difference between the two noun types was not significant for either group. The child L2 group performed equally well with higher and lower frequency neuter nouns. It is possible that this latter result might stem from the contexts in the 'Spoken Dutch corpus' being less relevant to children than adults. It should be noted furthermore that the frequency calculation is based on the relative frequency of the nouns produced in the picture description task. A complete investigation of the effects of frequency would require this variable to be systematically manipulated. 


\section{Quality of input}

The third research question asked whether, following Hulk and Cornips' (2006a) suggestion that the fossilization observed in the ethnic community bilingual children in their study was due to the 'ethnic Dutch' input to which they were exposed, English-speaking L2ers would also fossilize whilst in an overgeneralization stage. It was hypothesized that given that the participants in the present study were unlikely to have been exposed to such input, no fossilization should be observed.

This prediction is borne out in the sense that there are learners who are targetlike, suggesting that targetlike acquisition of grammatical gender as marked by the definite determiner is, in principle, possible by Englishspeaking children and adults. However, there are many more nontargetlike L2ers. Many of these non-targetlike L2ers, especially those with a relatively short exposure, will probably still be in the process of acquiring gender and so their interlanguage grammars are unlikely to have fossilized. There are, however, a number of L2ers who have had a lengthy exposure to Dutch and who are nonetheless non-targetlike. If these learners have fossilized, it cannot be the result of being exposed to 'ethnic Dutch' input as suggested for ethnic minority children in previous research (Hulk and Cornips, 2006a). In Section III.5, other explanations that might contribute to this result are explored.

Three adults and one child have Pattern 6 , consistently producing het with neuter nouns and $d e$ with common nouns, albeit to not quite the same level as native speakers. This finding suggests that the acquisition of syntactic gender (when this is not present in the L1) is not impossible, corroborating some previous findings (White et al., 2004; compare Franceschina, 2005).

\section{Use of het with common nouns}

It was observed that several participants sometimes use het with common nouns. An analysis of individual consistency patterns revealed that for most learners, however, this was restricted to certain nouns only. Although there was some evidence of systematic overgeneralization, this was restricted to just three children, who produced het with most or all common nouns (for a similar observation for older Moroccan/ Turkish L2/2L1 children, see Cornips et al., 2006). Note, however, that 
these children's responses could also (in part) result from miscategorization of common nouns as neuter. In total, approximately a quarter of all neuter nouns were produced with both de and het. It was suggested that learners may not yet have specified these nouns for gender.

\section{Possible explanations for non-targetlike learners}

Although there are some participants who consistently produce de with common nouns and het with neuter nouns, the vast majority overgeneralize de to neuter nouns. For some, this may be the result of their relatively low proficiency level. For others, however, this overgeneralization persists despite having had a relatively long and intensive exposure. Given that some learners are able to acquire gender, the lack of a gender feature in English cannot be the reason for this non-targetlike behaviour. There are three possible explanations.

The first relates to the age factor. Several researchers have suggested that learners have to reach the relevant threshold in the input within a certain, age-related timeframe in order for acquisition to be successful (on the acquisition of Dutch gender, see Blom et al., 2007; Cornips and Hulk, this issue; Hulk, to appear; on threshold effects in bilingualism in general, see Sorace, 2005). If we assume that the relevant timeframe in this case is the timeframe within which monolinguals acquire het - that is, by about age six - then all learners first exposed to Dutch when older than six should be non-targetlike, quite simply because they will not have had any input in the relevant timeframe. In the present study, there were five child participants whose age of first exposure was seven and only one uses het (with 5/10 neuter nouns). However, a review of the individual data for these children reveals that they have all had a short and limited/moderate exposure to Dutch. Given the observation made above that the targetlike learners have all had a lengthy and relatively intense exposure to Dutch, it is unlikely that these five children, with considerably less exposure, would be targetlike anyway, even if there were no threshold at age six. Clearer data come from the adult participants. The observation that there are some adults who consistently produce the target gender-marked determiner is counter-evidence to the claim that learners must reach the relevant threshold in the input within a certain, age-related timeframe. If age (combined with sufficient input) 
is the crucial factor in determining success in the acquisition of grammatical gender in Dutch, there should be no targetlike learners whose age of first exposure is beyond the relevant timeframe. The targetlike adults in the present study were first exposed to Dutch at age 23 or older.

The second possible explanation for the observation that most participants overgeneralize de even after relatively lengthy and moderately intense exposure is that, quite simply, they need more exposure. Most of the (more or less) targetlike participants have had a lengthy and (relatively) intense exposure, suggesting the importance of input for the acquisition of this particular property of Dutch. The trend observed in the frequency data, namely that het was produced more often with 'higher' frequency nouns than with 'lower' frequency nouns, is indicative of an input effect and it is consistent with previous studies (Sabourin et al., 2006; Brouwer et al., 2008).

To ascertain the gender of a given noun, a language learner's most salient clue will be the definite determiner (Carroll, 1989). As noted in Section I.1, however, the neuter definite determiner is significantly less frequent in the input than the common definite determiner. The relative low frequency of the neuter determiner is, of course, a constant factor across monolingual and bilingual populations. However, bilinguals are exposed to less language input than monolinguals, by virtue of their bilingualism. If monolingual L1 children need around six years of input to acquire grammatical gender in Dutch, and if input is the crucial factor in the acquisition of this particular property of Dutch, then bilinguals will need significantly more input. If, for the sake of argument, we assume that the bilinguals are exposed to Dutch for around half the time, and to English for the other half, then this will mean that they would need at least 12 years of exposure to Dutch in order to be on a par with monolinguals. ${ }^{9}$ It turns out that the only targetlike child in the present study is one of the few participants who had had approximately this number of years of input (11 years, including one at Dutch nursery). Two of the three adults who consistently mark gender on determiners have had 13 and 25 years of exposure, respectively, and

\footnotetext{
${ }^{9}$ For many of the children in the present study, this calculation is too generous: given that they attend (predominantly) English-speaking international schools and (mostly) live with English speakers, more than half of the input to which these children are exposed is likely to be in English.
} 
the third had just five years of exposure. It is possible that for this latter participant, who is exposed to Dutch considerably more than to English, the calculation made above is inaccurate. ${ }^{10}$ The data suggest that in order to acquire grammatical gender, long and extensive exposure to Dutch is probably necessary; the observation that there are participants with long (and also extensive) exposure who remain non-targetlike (compare Table 3) indicates that such exposure is not, however, sufficient.

The third possible explanation for the widespread overgeneralization of $d e$ is that learners adopt the default form because they have problems realizing the appropriate surface form (Lardiere, 2000; Bruhn de Garavito and White, 2002; on L1 Dutch, see also van der Velde, 2003). On this account, common nouns are marked with the appropriate [- neuter] feature, which is checked or valued against the [-neuter] feature on the determiner. Neuter nouns, on the other hand, are marked with the appropriate $[+$ neuter] feature, but this can be checked or valued against either a targetlike [ + neuter] feature on the determiner or the default [ - neuter feature]. On this approach, the gender specification of neuter nouns is correct in the learners' interlanguage grammars, but they experience problems in realizing the correct form of the determiner in production (see also White et al., 2004; Brouwer et al., 2008). This may account for some of the errors that L2ers make; other errors may be due to a failure to specify a given noun for gender at all, which may in principle result in overgeneralization in either direction, or to the miscategorization of a noun in terms of its gender specification.

\section{Conclusions}

Data were collected from English-speaking children and adults acquiring Dutch to determine whether they could successfully acquire grammatical gender agreement between the noun and definite determiner. L2 development in this domain was found to share both similarities and differences with monolingual L1 development. The results indicated that consonant with previous studies - the participants in the present study

\footnotetext{
${ }^{10}$ Type/intensity of exposure and length of exposure were calculated separately here but, essentially, they reflect two sides of the same coin: more intensive exposure is equivalent to longer exposure. A more accurate measure of input would combine both into one measure.
} 
overgeneralized the common determiner de to neuter nouns. In contrast to monolingual children, however, a small number of participants were also observed to use the neuter determiner het with common nouns. This result suggests that this pattern, also observed with older ethnic community bilinguals (for relevant discussion, see Cornips and Hulk, this issue), may be a typical characteristic of the L2 acquisition of grammatical gender in Dutch. Whether persistent overgeneralization of de with neuter nouns - that is, fossilization in this stage - is also a typical characteristic of L2 acquisition remains unclear. The English-speaking participants in the present study were not exposed to the 'ethnic Dutch' characteristic of the input of ethnic community bilingual children from previous studies and, hence, this cannot be a factor in their nontargetlike behaviour. Furthermore, there were a handful of L2ers who used the target determiner het with neuter nouns to the same extent as native speakers. These learners had all had a lengthy and relatively intensive exposure to Dutch. It was suggested, therefore, that a lengthy and extensive exposure may be necessary for targetlike acquisition. It cannot be sufficient, however, because there were several L2ers who had a similar length and type of exposure but who remained non-targetlike.

A clear finding in the present study is the lack of age effects. Although the only targetlike participant on both neuter and common nouns belonged to the child group, there were both children and adults who produced het with neuter nouns to the same extent as native speakers. On the whole, the adults performed better than the children. The agerelated deficits observed in previous work on the acquisition of Romance languages were thus not replicated here. This may be expected if, as suggested by an anonymous reviewer, the present results are interpreted as evidence for the acquisition of nominal gender and determiner concord relating more to vocabulary than to grammar acquisition per se (for related discussion, see Blom et al., this issue).

The data presented in this article suggest the following developmental sequence for the acquisition of grammatical gender in Dutch by English-speaking children and adults. In the initial stages of development, de is produced with both common and neuter nouns. For these learners, this could be the result of transfer as well as of overgeneralization of the default form: the English definite determiner the is phonologically more similar to the common determiner de than to 
the neuter determiner het. At this stage, grammatical gender does not exist in the L2er's interlanguage grammar. Subsequently, learners notice that determiners are variable and that this variability depends on the noun (Carroll, 1989). For Dutch, this means that they notice that another definite determiner, het, exists and they start to produce het with certain neuter nouns. At this stage, then, the interlanguage grammar may be said to instantiate the category of grammatical gender. Learners must now specify the nouns already in their lexicon - as well as any nouns which they subsequently acquire - as either [ + neuter] or [ - neuter]. During this process of specification, it is to be expected that not only will de be used with neuter nouns but het may also be used with common nouns (for similar predictions, see Cornips and Hulk, this issue). Furthermore, after first encountering a noun in the input, it may take learners some time to specify the gender of that noun in its lexical entry. Given that L2ers are often in the process of acquiring new nouns, this means that they may regularly commit a limited - but not necessarily insignificant number of errors in their production of gender-marked determiners. Longitudinal data is of course necessary to confirm whether the proposed developmental sequence is along the right lines.

\section{Acknowledgements}

Various versions of this article were presented at GALANA 2, ISB 6 and EUROSLA 17. I would like to thank the audiences there for their useful suggestions. In particular, I would like to thank the following people, as well as three anonymous Second Language Research reviewers, for their insightful comments: Elma Blom, Suzanne Carroll, Theo Marinis, Daniela Polišenská and Mike Sharwood Smith. Thanks also to Femke Voncken for transcribing the adult data.

\section{References}

Anderson, R. 1999: Loss of gender agreement in L1 attrition: preliminary results. Bilingual Research Journal 23, 319-38.

Andersson, A.-B. 1992: Second language learners' acquisition of grammatical gender in Swedish. Unpublished PhD thesis, University of Göteborg, Sweden.

Bartning, I. 2000: Gender agreement in L2 French: pre-advanced vs. advanced learners. Studia Linguistica 54, 225-37.

Bley-Vroman, R. 1990: The logical problem of foreign language learning. Linguistic Analysis 20, 3-49. 
Blom, E., Polišenská, D. and Weerman, F. 2007: Variation in inflection: a comparison of agreement inflection in child L1, child L2 and adult L2 Dutch. Morphology 16, 313-36.

— this issue: Articles, adjectives and age of onset: the acquisition of Dutch grammatical gender. Second Language Research 24.

Brouwer, S., Cornips, L. and Hulk, A. 2008: Misrepresentation of Dutch neuter gender in older bilingual children? In Gavruseva, E. and Haznedar, B., editors, Current trends in child second language acquisition: a generative perspective. Amsterdam: John Benjamins.

Bruhn de Garavito, J. and White, L. 2002: The second language acquisition of Spanish DPs: the status of grammatical features. In Pérez-Leroux, A.T. and Munoz Liveras, J., editors, The acquisition of Spanish morphosyntax. Dordrecht: Kluwer, 153-78.

Carroll, S.E. 1989: Second-language acquisition and the computational paradigm. Language Learning 39, 535-94.

- 1999: Putting 'input' in its proper place. Second Language Research $15,337-88$.

Carstens, V. 2000: Concord in minimalist theory. Linguistic Inquiry 31, 319-55.

Corbett, G. 1991: Gender. Cambridge: Cambridge University Press.

Cornips, L. 2002: Ethnisch nederlands [Ethnic Dutch]. In Bennis, H., Extra, G., Muysken, P. and Nortier, J., editors, Een buurt in beweging: talen en culturen in het Utrechtse Lombok en Transvaal [A changing district: languages and cultures in Utrecht's Lombok and Transvaal neighbourhoods]. Amsterdam: Aksant, 285-302.

Cornips, L. and Hulk, A. 2005: Bilingual acquisition and 'fossilization' versus 'acceleration' of grammatical gender agreement of the definite article. Unpublished manuscript, Meertens Institute, University of Amsterdam.

— this issue: Factors of success and failure in the acquisition of grammatical gender in Dutch. Second Language Research 24.

Cornips, L., van der Hoek, M. and Verwer, R. 2006: The acquisition of grammatical gender in bilingual child acquisition of Dutch (by older Moroccan and Turkish children): the definite determiner, attributive adjective and relative pronoun. In Los, B. and van de Weijer, J., editors, Linguistics in the Netherlands 2006. Amsterdam: John Benjamins, 40-51.

De Houwer, A. 1990: The acquisition of two languages from birth: a case study. Cambridge: Cambridge University Press.

Deutsch, W. and Wijnen, F. 1985: The article's noun and the noun's article: explorations into the representation and access of linguistic gender in Dutch. Linguistics 23, 793-810.

Dewaele, J.-M. and Véronique, D. 2001: Gender assignment and gender agreement in advanced French interlanguage: a cross-sectional study. Bilingualism: Language and Cognition 4, 275-97. 
Donaldson, B.C. 1987: Dutch reference grammar. Leiden: Martinus Nijhoff.

Franceschina, F. 2005: Fossilised second language grammars: the acquisition of grammatical gender. Amsterdam: John Benjamins.

Geerts, G., Haeseryn, W., de Rooij, J. and van de Toorn, M.C. 1984: Algemene nederlandse spraakkunst [A general grammar of Dutch]. Groningen: Wolters-Noordhoff.

Guillelmon, D. and Grosjean, F. 2001: The gender marking effect in spoken word recognition: the case of bilinguals. Memory and Cognition 29, 503-11.

Hawkins, R. and Chan, C.Y.-H. 1997: The partial availability of Universal Grammar in second language acquisition: the 'Failed functional features hypothesis'. Second Language Research 13, 187-226.

Hawkins, R. and Franceschina, F. 2004: Explaining the acquisition of and non-acquisition of determiner-noun gender concord in French and Spanish. In Prévost, P. and Paradis, J., editors, The acquisition of French in different contexts: focus on functional categories. Amsterdam: John Benjamins, 175-205.

Hulk, A. to appear: Deviance in early child bilingualism. In Cabrera, M.J., Camacho, J., Déprez, V., Flores, N. and Sánchez, L., editors, Selected Proceedings of the 36th Linguistic Symposium on Romance Languages. Amsterdam: John Benjamins.

Hulk, A. and Cornips, L. 2006a: The acquisition of definite determiners in child L2 Dutch: problems with neuter gender nouns. In Unsworth, S., Parodi, T., Sorace, A. and Young-Scholten, M., editors, Paths of development in L1 and L2 acquisition. Amsterdam: John Benjamins, $107-34$.

- 2006b: Between 2L1 and child L2 acquisition: an experimental study of bilingual Dutch. In Lleó, C., editor, Interfaces in multilingualism: acquisition, representation and processing. John Amsterdam: Benjamins.

Hyltenstam, K. 1992: Non-native features of near-native speakers. In Harris, R.J., editor, Cognitive processes in bilinguals. Amsterdam: North Holland, 351-68.

Hyltenstam, K. and Abrahamsson, N. 2003: Maturational constraints in SLA. In Doughty, C. and Long, M.H., editors, The handbook of second language acquisition. Oxford: Blackwell, 539-88.

Lardiere, D. 2000: Mapping features to forms in second language acquisition. In Archibald, J., editor, Second language acquisition and linguistic theory. Oxford: Blackwell, 102-29.

Montrul, S. and Potowski, K. 2007: Command of gender agreement in school-age Spanish-English bilingual children. International Journal of Bilingualism 11, 301-28.

Prévost, P. and White, L. 2000: Missing surface inflection or impairment in second language acquisition? Evidence from tense and agreement. Second Language Research 16, 103-33. 
Rogers, M. 1987: Learner's difficulties with grammatical gender in German as a foreign language. Applied Linguistics 8, 48-74.

Sabourin, L. and Stowe, L.A. this issue: Second language processing: when are first and second languages processed similarly? Second Language Research 24.

Sabourin, L., Stowe, L.A. and de Haan, G.J. 2006: Transfer effects in learning a second language grammatical gender system. Second Language Research 22, 1-29.

Sorace, A. 2005: Selective optionality in language development. In Cornips, L. and Corrigan, K., editors, Syntax and variation: reconciling the biological and the social, Amsterdam: John Benjamins, 55-80.

Umbel, V. and Oller, D.K. 1995: Developmental changes in receptive vocabulary in Hispanic bilingual school children. In Harley, B., editor, Lexical issues in language learning. Amsterdam: John Benjamins, 29-80.

Unsworth, S. 2005: Child L1, adult L2, child L1: differences and similarities: a study on the acquisition of direct object scrambling in Dutch. Doctoral dissertation, Utrecht University. Dissertation series 119. Utrecht: LOT.

2007: Age and input in early child bilingualism: the acquisition of grammatical gender in Dutch. In Belikova, A., Meroni, L. and Umeda, M., editors, GALANA 2: Proceedings of the conference on Generative Approaches to Language Acquisition North America 2. Somerville, MA: Cascadilla Press, 448-58.

2008: Comparing child L2 development with adult L2 development: how to measure L2 proficiency. In Gavruseva, E. and Haznedar, B., editors, Current trends in child second language acquisition: a generative perspective. Amsterdam: John Benjamins, 301-33.

van Berkum, J.J.A. 1996: The psycholinguistics of grammatical gender: Studies in language comprehension and production. Unpublished $\mathrm{PhD}$ thesis, Max Planck Institute for Psycholinguistics, Nijmegen.

van der Velde, M. 2003: Déterminants et pronoms en néerlandais et en français: syntaxe et acquisition [Determiners and pronouns in Dutch and French: syntax and acquisition]. Unpublished doctoral dissertation, University of Paris 8, France. Available online at http://umr7023. free. fr/Downloads/MvdVeldeTh_somm.html (March 2008).

-2004: L'acquisition des déterminants en L1: Une étude comparative entre le français et le néerlandais. Acquisition en Interaction en Langue Etrangère 21, 9-46.

Verrips, M. and Wijnen, F. 1998: The acquisition of Dutch syntax. In Gillis, S. and De Houwer, A., editors, The acquisition of Dutch. Amsterdam: John Benjamins, 223-300.

White, L., Valenzuela, E., Kozlowska-MacGregor, M. and Leung, Y.-K.I. 2004: Gender and number agreement in nonnative Spanish. Applied Psycholinguistics 25, 105-33. 